ISSN 2658-4824 (Print)

УДК 78.08

DOI: 10.33779/2658-4824.2020.1.046-056

\section{Г.С. ГАЛИНА}

Уфимский государственный институт искусств им. Загира Исмагилова

2. УФа, Россия

ORCID: 0000-0003-1297-5641

gulnazgalinas3@yandex.ru

\section{GULNAZ S. GALINA}

Ufa State Institute of Arts named after Zagir Ismagilov

Ufa, Russia

ORCID: 0000-0003-1297-5641

gulnazgalinas3@yandex.ru

\section{Роль городской культуры в формировании башкирского национального искусства дореволюционного периода}

В статье приводятся основные сведения по развитию городской музыкальной культуры Оренбургской губернии и Уфы в дореволюционный период. Закономерность формирования феномена городской культурной среды прослеживается на примере таких её компонентов, как концертная и театральная практика. В их контексте оттачивались необходимые для развития европейских жанров основы композиторского и исполнительского профессионализма. В результате обзора различных форм домашнего музицирования и концертно-театральной практики, основы которых были заложены непосредственными носителями самой европейской культуры - польскими повстанцами, сосланными в губернию в XVIII веке, обосновывается факт того, что русско-европейская академическая традиция подготовила почву, на которой в начале XX века зародилась национальная концертная и театральная жизнь. Доказывается, что европеизация в башкирской культуре началась не в период советского культурного строительства, а на волне джадидизма в деятельности новометодных медресе, ставших в начале прошлого века основными очагами духовной и светской культуры. Возникновение же совместных татаро-башкирских драматических

\section{The Role of City Culture in the Formation of the Bashkir National Art of the Pre-Revolutionary Period}

The article presents some basic information about the development of city musical culture in the Orenburg gubernia and in Ufa during the pre-revolutionary period. The regularity of the formation of the phenomenon of the city cultural milieu is traced by the examples of such components as concert and theatre practice, in the context of which the foundations of compositional and performance professionalism indispensable for the development of European genres were perfected. As the result of an overview of various forms of musicmaking at home and the concert and theater practice, the foundations of which had been installed by the direct bearers of European culture itself - Polish insurgents banished to the gubernia in the 18th century - the fact is substantiated that the Russian-European academic musical tradition conditioned the environment due to which national concert life was established in the early 20th century. It is proven that the Europeanization in Bashkir culture began not during the period of the Soviet cultural development, but on the wave of Jadidism in the activities of the new-method madrassahs, which in the beginning of the previous century became the main centers for sacred and secular culture. At the same time, the emergence of combined Tatar-Bashkir dramatic theatrical troupes conducive towards the onset of national theatrical music is the greatest 
трупп, способствовавших зарождению национальной театральной музыки, есть самое большое достижение башкирской музыки в дореволюционный период, связавшей дореволюционную эпоху с периодом становления национальных композиторских школ.

\section{Ключевые слова:}

городская культура, концертно-театральная жизнь, европейское академическое исполнительство, национальный концерт. accomplishment of Bashkir music in the prerevolutionary period, which connected the pre-revolutionary epoch with the period of formation of national compositional schools.

Keywords:

city culture, concert and theater life,

European classical musical performance, national concert.

\section{Для иитирования/For citation:}

Галина Г.С. Роль городской культуры в формировании башкирского национального искусства дореволюционного периода // ИКОНИ / ICONI. 2020. № 1. С. 46-56.

DOI: $10.33779 / 2658-4824.2020 .1 .046-056$.

$\mathrm{H}$ аиважнейшим условием ассимиляции академических жанров в национальную культуру является наличие развитой городской культуры и успешное функционирование музыкальной инфраструктуры с разветвлённой системой театров, концертных залов, музыкальных учебных заведений. Так, к началу советского периода в культурном пространстве Башкирии сложилась развитая академическая профессиональная традиция, конкретным проводником которой в российской провинции стала доминирующая русская культурно-языковая сфера. После вхождения Башкирии в состав Российского государства именно она стала главным посредником в транскультурной коммуникации и особенно активно развивалась в крае в течение полутора столетий, предшествующих советскому периоду. В её пространстве в Башкирии (Уфе, Оренбурге, Орске, Троицке и др. городах) зародились многие формы национальной концертно-театральной жизни, ставшие важной предпосылкой для возникновения в музыке национальной академической традиции. Этот процесс начался после революции 1905 года и особенно интенсивное развитие получил в Уфе после того, как она стала столицей Большой Башкирии (1922).

Как и в других российских регионах, в Башкирии, начиная с XVIII века, очень динамично развивается музыкальная жизнь в различных её проявлениях и формах. Этот пласт музыкальной истории подробно описан исследователями. Первоначальная фактология культурной жизни Уфы дореволюционного периода собрана Л.П. Атановой [1]; музыкальный быт семьи Аксаковых, проживавших в Уфе и с. Надеждино Белебеевского уезда Уфимской губернии, - Л.В. Носоревой [13]; события музыкальной жизни Уфы, свидетельствующие о предпосылке возникновения фортепианного исполнительства и башкирской фортепианной музыки, - Н.Ф. Гариповой [4]. Эпоха советского культурного строительства (20-30-е годы XX века) описана Г.А. Коваленко [10]; музыкальная культура Оренбургского края в широком историческом контексте, основанная на архивных материалах, - Б.П. Хавториным [16]. В соотнесении с традициями восточной (исламской) культуры, в результате чего прослеживается идея влияния евразий- 
ства, проведено исследование 3.А. Имамутдиновой [5]; концертно-театральная практика Оренбурга как условие зарождения национальной музыкальной культуры представлена Е.К. Карповой [7-9] и М.А. Идрисовой [3].

Наиболее важное историческое значение как показатель особенностей развития городской провинциальной культуры имела огромная Оренбургская губерния (с 1865 года и Уфимская), которая была местом ссылки политзаключённых. Именно они по преимуществу составили аристократический слой местного городского населения. Если в Оренбурге, построенном как военная крепость для укрепления юго-восточной границы Российской империи, преобладали военные и торговцы, то Уфа, по словам краеведа С. Синенко, среди всех городов Урала в XVIII-XIX вв. была самым дворянским городом с большим числом ссыльных и опальных дворян, т. е. людей образованных и свободомыслящих (16 \% всех уфимских дворов, в 1864 г. - 19 \%) [14, с. 87]. Основными носителями европейской культуры в крае были губернатор и его окружение, любившие всяческие увеселения. Зародившись в узком кругу приближённых, инструментальное, вокальное и ансамблевое домашнее музицирование постепенно способствовали развитию бальной, театральной, хоровой и парковой музыки. Как следует из обзора упомянутых исследований, концертно-театральная жизнь более активно протекала в Уфе, бально-танцевальная и парковая - в Оренбурге, и этому есть своё объяснение. Уфа географически находилась ближе к центру, и процент дворян, обеспечивающих функционирование музыки в верхнем слое иерархической системы (академическая музыка), в ней был выше. В Оренбурге как административном центре всего края находилась резиденция военного губернатора, поэтому светские приёмы и балы, устраиваемые там по образцу столичных в специально построенной галерее, отли- чались роскошью, особенно когда туда приезжали царствующие особы.

Традиции городского музицирования в крае были заложены непосредственными носителями академической музыкальной культуры, самими иностранцами - польскими повстанцами-конфедератами, высланными в Уфу в 1772 году. Поставленный ими в доме мензелинского воеводы Н. Можарова музыкальный спектакль «Пан Бронислав» на специально построенной для этого сцене, дал важный импульс для развития всей музыкально-театральной жизни города и продемонстрировал перенесение на иную национальную почву европейской театральной модели, независимо от того, какого качества она была. Многие из ссыльных стали гувернёрами, компаньонами, настройщиками музыкальных инструментов, педагогами, обучавшими музыке уфимскую молодёжь. Пребывание в крае поляков, а позже и других политзаключённых (вторая партия прибыла в 1831 году) заложило основы домашнего музицирования, бывшего в течение долгого времени едва ли не единственным развлечением местного дворянского общества.

Существенное влияние на развитие культуры в крае в XIX веке оказали и около полутора тысячи пленённых французов, размещённых по городам и крепостям Оренбургской пограничной линии. Многие из них преподавали французский язык в гимназиях, участвовали в самодеятельных спектаклях любительского театра (1843). «Роль «иноземщины» была велика по всей России», — пишет со ссылкой на Т.Н. Роменскую, обозревшую деятельность пленных шведов в Сибири, 3. Имамутдинова [5, с. 58]. Опера, балет, симфонические и инструментальные сочинения первоначально внедрялись в сознание россиян иностранцами, далее - самими россиянами.

Наиболее активно формирование городской культурной жизни с её неоднородностью вкусов и художественных 
запросов происходило в первой половине XIX века, во времена правления военных губернаторов Оренбургского края генерал-аншефа, князя Г.С. Волконского (1803-1817) и генерала, графа В.А. Перовского (1833-1842, 1851-1857). Волконский - известный в истории Башкирии, прежде всего, своим предписанием к башкирам встать на защиту Отечества в 1812 году, прославился не только своими военными подвигами, но и светскими балами, фейерверками, пушечной стрельбой и народными гуляниями, перенесёнными из столицы в провинцию. Он являлся любителем, знатоком и пропагандистом классической музыки. Именно он познакомил Оренбургское общество с творениями итальянских композиторов Б. Марчелло, Д. Палестрины, Д. Перголези, А. Страделлы. Центрами развития и пропаганды классической музыки в Оренбурге стали музыкальные салоны в генеральских домах А. Жемчужникова, А. Толмачёва и И. Стеллиха, где давались домашние концерты камерной музыки, несколько позже - дом военного инженера, астронома и геодезиста И.Ф. Бларамберга. В начале XVIII века в городе сложилась группа из числа музыкантов-любителей: пианистка Г. Габбе, певец и пианист П. Потапов, певцы А. Росси, Н. Дурасов, сёстры-пианистки Стеллих и т. Д. - преимущественно из числа военных [16, с. 128].

Из жанров бальной музыки «наиболее распространённым видом семейного музыкального времяпровождения являлись «ассамблеи», то есть вечера с танцами, на которых присутствовали чиновники, военные, а также молодёжь в сопровождении родителей, устраиваемые ежедневно» [16, с. 24]. Обслуживали балы духовые оркестры, формирование которых началось в губернии с 30-х гг. XVIII века по велению императрицы Анны. Традиционным местом их выступлений в Уфе были городской сад (впоследствии Видинеевский, им. Луначарского и С.Т. Аксакова), Ушаковский парк (1867, позже парк им. А. Матросова); в Оренбурге - Зауральная роща, где ещё во времена губернатора П. Эссена (1817-1830) была выстроена ротонда (каменная беседка), специально предназначенная для выступлений военных и гражданских оркестров. Событием в жизни края стал насыщенный смотрами, приёмами и балами визит императора Александра I (1824), высочайшим присутствием которого были удостоены Оренбург, Уфа, Стерлитамак, Бирск, Илецкая защита. Строевые смотры, сопровождавшие подобные мероприятия и прочие торжества не мыслились без фанфар, виватов, кантов, менуэтов и полонезов [16, с. 128]. Традиции бытового музицирования закладывались и крепостными оркестрами, которые содержали крупные помещики Волковы, Селиверстовы, Тимашевы, Дурасовы, Пекарские. Их деятельность, носившая замкнутый характер, упоминается в разных публикациях по истории Башкирии XVIII века.

В середине XIX века формы музыкальной жизни становятся более разнообразными. Как и в российской культуре, знакомство с жанрами и формами европейской музыки в Башкирии также было связано с деятельностью первоначально иностранных, далее - русских гастролирующих оперных и драматических трупп: в Уфе - гастроли немецкой труппы в 1780-1790-е гг. с репертуаром из музыкальных комедий; гастроли известного в русской провинции труппы антрепренёра Н.А. Соколова в 1841-1843 гг., показавшей уфимцам модные тогда оперы «Цампа» Л. Герольда и «Алькольдова могила» А. Верстовского; антреприза Иванова, основу которой составляли водевили, и труппа Маркевича в 1849-1850 гг.; в Оренбурге - выступления труппы Г. Мекольда (1854), Б. Соловьёва (1856), солистов-исполнителей Ж. Гюлиоми (1835), Д. Севастьянова (1852), К. Шуберта (1857) [16, с. 130] и т. д. Из перечисленного вырисовывается определённая закономерность в функционировании жанров ака- 
демической музыки: перенесение, адаптация, усвоение.

Главными проводниками профессионального академического искусства с первой половины XIX века являлись Уфимское (1819-1917) и Оренбургское (1842) Благородные дворянские собрания (впоследствии многократно менявшие свои названия); “Общество любителей музыки, пения и драматического искусства» (1885-1906), Зимний и Летний театры, «Секция народного театра и распространения изящных искусств» в Уфе (1916), в которых музыке придавали очень важное значение. В Оренбурге музыкальное искусство пропагандировалось Музыкально-драматическим обществом, русским драматическим театром, краеведческим музеем, в Доме генералгубернатора и в саду Караван-Сарая и даже на железнодорожном вокзале, в котором был выстроен концертный зал. Событием стало создание симфонического оркестра Оренбургского казачьего войска [16].

В результате к концу XIX века публичные концерты, в которых выступают местные любители музыки и приезжие гастролёры, становятся систематическими и составляют норму культурной жизни горожан. В связи с этим уже можно говорить о сложившемся в дореволюционный период в Башкирии институте концерта, причём во всех его известных разновидностях: придворном, салонном, домашнем. В таком контексте историческим фактом расценивается дебют молодого Ф. Шаляпина в составе труппы С. Семёнова-Самарского (опера С. Монюшко «Галька», 1889), о чём достаточно много написано со ссылкой на воспоминания самого артиста «Маска и душа». Описывая уфимский период жизни Шаляпина, его сотрудничество с драматическим отделом уфимского «Общества любителей пения, музыки и драматического искусства", все авторы подчёркивают роль Уфы в творческом становлении великого русского певца. Этот красноречивый факт действительно обладает некоей исключительностью, создавая Уфе репутацию оперного города.

Постоянная концертно-театральная жизнь стала возможной благодаря сложившемуся во второй половине XIX века собственному корпусу профессиональных музыкантов-инструменталистов академического плана, не только из тех, кто волею судьбы оказался в Башкирии, но и из местных. Список первых начинается с имени Дм. Севастьянова (1827-1899) первого скрипача Большого театра в Москве, занимавшегося после известного пожара 1853 года активной концертной деятельностью и поселившегося в 1870 году в Уфе. Его дом стал центром музыкальной жизни всего города. Неоднократные концерты Севастьянова в Уфе и Оренбурге нашли отражение в местной печати, обильно цитируемой многими современными исследователями.

Примером местных исполнительских традиций служит творческая биография русской пианистки европейского масштаба Веры Тимановой (1855-1942), учившейся у уфимских педагогов М. Игнатович и Л.К. Новицкого (поляков), далее - у А. Рубинштейна в Петербурге, К. Таузига и Ф. Листа в Веймаре. Гастролируя по Европе, Турции и Америке, время от времени наезжала с концертами в родную Уфу, о чём сохранились рецензии в «Уфимских губернских ведомостях", часть которых опубликована. Отзыв П.И. Чайковского на одно из её московских выступлений приводит 3. Имамутдинова: «...она поразила меня, так же как и всю публику, ловким, пылким, блестящим исполнением превосходного мендельсоновского произведения...» (цит. по: [5, с. 44]). Своими выступлениями Тиманова утверждала в родном городе традиции европейского академического исполнительства.

Композиторское творчество в Башкирии развивается со времён ссылки в Оренбург русского композитора А.А. Алябьева (1833-1837), изучение которого 
вносит яркий штрих в общую биографию композитора. Если в историю русской музыки А. Алябьев вошёл как автор, написавший в Оренбургской ссылке 30 сочинений в различных жанрах (особенно камерно-инструментальном и вокальном) и заложивший тем самым в крае основы музыкального академического профессионализма, то в историю башкирской - как автор первых нотаций башкирской народной музыки и автор первых музыкальных сочинений на башкирскую тематику. Это «Башкирская увертюра» и вокальный цикл «Азиатские песни», посвящённый В.А. Перовскому и написанный на основе подлинных народных мелодий, две из которых - башкирские. Эти сочинения ныне расцениваются как ранние образцы русского музыкального ориентализма, заложившие в отечественной культуре широко развитую традицию обращения русских композиторов к образам Востока. Если ещё принять во внимание его исполнительскую деятельность (организацию духового оркестра, руководство струнным квартетом, дирижирование хором и др.), благодаря чему домашнее музицирование в крае заметно профессионализировалось, то уподобление этой работы композитора в провинциальных городах России «просветительской деятельности ссыльных декабристов» [6, с. 32], кажется очень справедливой. Своей попыткой освоить монодийную культуру, Алябьев предвосхитил деятельность русских композиторов в Башкирии.

Кульминацией формирования академических традиций в Уфе стали два крупнейших события: строительство Аксаковского народного дома (нынешнего Башкирского государственного театра оперы и балета), заложенного в 1909 году в связи с 50-летием со дня смерти С.Т. Аксакова (достроен в 1930-е годы) и открытие в 1914 г. Уфимского отделения Императорского Русского музыкального общества (ИРМО). Можно предположить, что не будь в истории революции 1917 года, театр в Уфе всё же был бы создан и существовал бы он в лоне русской культуры, как и многие другие музыкальные театры в России. Однако затянувшееся строительство здания Аксаковского дома словно перекинуло мостик от дореволюционной эпохи к периоду советского культурного созидания и здание достроили в 1935 году, сделав возможным обсуждения темы башкирской национальной оперы.

Открытие в Башкирии отделения Императорского русского музыкального общества (ИРМО) в Уфе и Оренбурге в 1914 году подняло музыкальное образование края на новый уровень, завершив тем самым период частной музыкально-педагогической практики. Многие из педагогов Общества приняли активное участие в культурных преобразованиях послереволюционной эпохи, создавая, прежде всего, социокультурные условия для развития национального искусства, а именно готовя национальные кадры краеугольный камень в проводимой советскими властями политике культурного строительства.

Таким образом, русско-европейская академическая традиция, прочно закрепившаяся в Башкирии за полуторавековой период своего развития, явилась перенесением традиции, сформировавшейся в иной социально-исторической среде. Она стала образцом, с которого срисовывался будущий образ национальной академической музыки. Этот процесс начался на заре XX века под непосредственным влиянием идей джадидизма («обновления») и естественным путём охватил многие сферы национальной литературы и искусства. В вечерах, особенно активно устраиваемых татарской и башкирской интеллигенцией после революции 1905 года, часто звучала и башкирская музыка. Но не на курае, а на рояле. Переориентации на европейские стандарты жизни и необходимости национального культурного развития способствовала реформация ислама в области 
просвещения - так называемый джадидизм Исмаил-бея Гаспринского, идеи которого в Башкортостане развивали крупнейшие религиозные деятели своего времени 3. Расулев, Р. Фахретдинов, 3. Камалетдинов, Х. Габяши, будущий татарский писатель и общественный деятель, уроженец Башкирии Г. Ибрагимов и др. Несмотря на различные подходы в рассмотрении этого явления, все авторы, в том числе и музыковеды, отмечают его положительное влияние на развитие национальной литературы и искусства, всей общественной жизни, благодаря чему вхождение в художественную практику европейского типа началось задолго до советского периода.

Культурными очагами в начале XX века и в Уфе, и в Оренбурге становятся медресе и другие учебные заведения с их музыкальными дисциплинами, а также драматические театры и музыкальные школы. Музыкальные уроки, введённые во всех гимназиях, училищах, медресе, ознаменовали решительный поворот к академизации музыкального образования. Так, в Уфимском реальном училище ученическим оркестром руководил дирижёр С.П. Копылов, откуда вышел Мансур Султанов (1875-1919) - первый и единственный до революции башкир-музыкант академического плана (окончил в 1903 г. Московскую консерваторию по классу флейты у В.В. Кречмана). Далее он работал в оркестре Большого театра в Москве и в Крыму, пока в 1912 г. не обосновался в Саратовской консерватории, где до конца жизни преподавал флейту и теорию музыки. Деятельность Султанова на благо башкирской культуры ограничивается его собирательской работой в области башкирского фольклора - составлением сборника «Башкирские и татарские мотивы» (Саратов, 1916), о чём подробно написано в книге Л.П. Атановой «Собиратели и исследователи башкирского музыкального фольклора» [2, с. 138-144]. Однако главное значение его для национальной культуры определяется тем, что именно он заинтересовал башкирской народной музыкой А.А. Эйхенвальда, активная работа которого привела к созданию первых башкирских опер.

В профессионализации городской культуры как на основе национальных музыкальных, так и европейских академических традиций особенно значительную роль сыграло уфимское медресе «Галия», которое стало не просто ярким образцом «новометодной» школы, но и национальным культурным центром всего Урала и Поволжья. Известно, что это учебное заведение в период с 1906 по 1920 годы окончили 1500 человек, из них только 37 стали служителями культа, остальные - учителями, писателями, учёными, музыкантами и артистами, многие из которых закладывали основы башкирского профессионального искусства [11, с. 238]. Ценные воспоминания, касающиеся общей атмосферы в медресе, музыкальных уроков, занятий в хоре и театральном кружке, поэтических вечеров, оставил выпускник этого медресе, Народный поэт Башкортостана Сайфи Кудаш [11, с. 203]. Понятие «театр шакирдов», благодаря организованному Г. Ибрагимовым кружку «Национальные мелодии, сцена и литература», зародилось именно здесь. Как пишет А.Л. Маклыгин, новометодные медресе на образ деревенской жизни особо не влияли, но включались в систему городской национальной жизни, формируя светские нормы культурной деятельности [12, с. 149].

Из всего многообразия предпосылок для развития профессиональной музыки, зародившихся в медресе, необходимо особо выделить традицию пения шакирдами стихов башкирских и татарских поэтов (Х. Салихова, М. Гафури, Ш. Бабича) на книжные напевы, о чём также пишет С. Кудаш [11, с. 198]. В предреволюционные годы такое пение, несмотря на противодействие мулл, действительно принимало широкий размах и причина этого - в ориентации на европейские формы искусства. Сведения о концер- 
тах, данных хорами шакирдов в Казани, Троицке, Чистополе, собрала В. Юнусова, которые она рассматривает в контексте национального музыкального образования $[17$, с. 40]. Хотя академизация баитов и мунажатов не успела пустить на башкирской почве глубоких корней, так как наступившая советская эпоха полностью переориентировала цели и формы хорового искусства, усмотреть в пении шакирдов предпосылку для ассимиляции академических жанров европейской традиции вполне возможно. Учащиеся из башкир и татар ещё до революции приобщались к европейской музыке, к атрибутам музыкального театра - хору и оркестру через её слушание и исполнение.

Результатом новой культурной ориентации явились и зародившиеся в городах Оренбургского края первые национальные драматические труппы, возникшие на основе богатейшего опыта театральной практики, имевшей место в XIX-XX веках. Возникновение этих коллективов, сыгравших решающую роль в становлении, как татарского, так и башкирского театров, следует считать высшим достижением этих культур в дореволюционный период. Прежде всего, это организованная в 1905 году в Оренбурге, первая в России полупрофессиональная татаро-башкирская театрально-драматическая труппа под руководством И. Кудашева-Ашкадарского, выступавшая под названием «Мусульманская драма и мелодрама». Из этого коллектива в 1906 году в Уральске выделилась коллективная антреприза «Сайяр» во главе с зав. труппой Г.Х. Хайруллиным-Кариевым, из которой в свою очередь, отделились сценические коллективы "Нур» во главе с С.Г. Гизатуллиной-Волжской (1912), «Ширкэт» под управлением Муртазина-Иманского (1915), «Театр ПОАРМ-1», «Театр ПОАРМ-5» и др. [15, с. 510]. Все они в будущем путём различных реорганизаций войдут в состав как Башкирского, так и Татарского драматического театров. Можно смело утверждать, что «окно в Европу» для башкирской, как и для татарской музыкальной культуры открыла не революция, а джадидизм. Но реализовала планы джадидистов, всё же революция, и реализовала по-своему.

В совместных татаро-башкирских постановках Оренбургского восточного театра, где ставились спектакли по первым пьесам будущих основоположников национальной драматургии Мухаметши Бурангулова и Мирхайдара Файзи, зародился жанр этнографической мелодрамы и татарской музыкальной драмы, сыгравших основополагающую роль для национальной оперы. В спектакли этого театра включались многочисленные обработки башкирских и татарских народных песен, сделанные оренбургскими музыкантами. Это хоры, вокальные ансамбли (дуэты, трио), музыка, звучавшая в антрактах между действиями с участием хора и оркестра. Постоянно звучал курай. Руководил музыкальной частью театра скрипач, гармонист С. Мифтахов. Именно в Оренбургских постановках зародились национальные оркестры, куда входили скрипки, мандолины, гармоники, балалайки, гитары, иногда - флейты и фортепиано. Как результат, именно в Оренбурге были заложены традиции национальной театральной музыки, впоследствии продолженные в Башкирском драматическом театре заведующими музыкальной частью театра Х. Ибрагимовым (1919-1932) и М. Валеевым (1932-1956).

В подготовке башкирской оперы исключительную роль сыграла Оренбургская Школа восточной музыки, организованная по инициативе преподавателей медресе «Хусаиния» и действующий при ней драматический кружок, созданный с «целью подготовки работников сцены, дабы расширить сценическую деятельность в большем масштабе среди мусульманского пролетариата и, ожидая в будущем от музыкальной школы создания мусульманской оперы (выделено мной - Г.Г.), подготовить оперных артистов» [3, с. 11]. Педагогический 
коллектив её составляли музыканты, по большей части приехавшие из Москвы и Петрограда во время послереволюционного хаоса [9, с. 12-13]. Просуществовав всего около трёх лет (1919-1921), школа, тем не менее, выполнила свою задачу по музыкальному воспитанию детей мусульман, ибо из неё вышел Масалим Валеев - автор первой башкирской оперы «Хакмар» и первый председатель Союза композиторов Башкирии.

Как видно из сказанного, башкирская профессиональная музыка часто проникает и начинает развиваться в городской среде автономно от процесса ассимиляции европейских форм музицирования, благодаря её тесной связи с татарской музыкой. К 1917 году, с которого принято вести отсчёт новейшей истории и в области музыкального искусства, в рамках городской культуры края формируются условия для становления музыкального профессионализма европейского типа. Названные представители татарской интеллигенции, выросшие в Башкирии и участвовавшие в различных формах городского национально-бытового музицирования, и стали зачинателями башкирской профессиональной музыки. Первое поколение национальных композиторов составили музыканты, прошедшие практику концертно-инструментального исполнительства, музыкальной педагогики и сочинительства музыки в классических европейских жанрах, как в устной, так и в письменной форме.

В биографии единственного башкирского музыканта того времени, ставшего лидером оперного движения в Татарстане и Башкортостане, Газиза Альмухаметова (1895-1938) удачно сочетаются деревенское детство в родном Куюргазинском районе, когда на слух им был усвоен значительный фольклорный фонд озон-кюй, и городское отрочество и молодость в Ташкенте, когда произошло окончательное формирование певца. Первые выступления Альмухаметова в Оренбурге, Стерлитамаке и Уфе, отно- сящиеся к лету 1916 и 1917 годов, когда на академическую сцену была выведена башкирская народная песня, как и концертные выступления Султана Габяши в Уфе и концертно-драматические представления смешанных татаро-башкирских театральных коллективов в начале века, позволяют говорить о дореволюционном этапе функционирования в Башкирии такой новой формы музыкальной жизни, как национальный конщерт.

Характерно, что музыкальные традиции так же, как театральные и литературные, в тот период развивались в тесных контактах коллективов Уфы, Оренбурга и Казани. По сути, все первые музыканты, закладывавшие основу башкирской и татарской музыки (В. Виноградов, А. Эйхенвальд, И. Козлов, А. Ключарёв, М. Музафаров, 3. Яруллин, Г. Альмухаметов, С. Габяши, К. Рахимов, М. Валеев), работали (или поработали) и в Уфе, и в Казани, многие - и в Оренбурге. Размежевание происходило в послереволюционные годы в связи с территориальной коррекцией функционирования национальных культур, когда таковые стали соответствовать пространству той или иной национально-государственной автономии. На первый план выдвигаются столицы созданных автономных и союзных республик. Оренбург же теряет своё значение как культурный центр народов Востока и далее развивается в лоне российской культуры с широкой сетью различных учреждений культурного профиля. Формы национальной концертно-театральной жизни, начиная с 20-х годов, в связи с переносом столицы Башкирии в Уфу, перемещаются в новую столицу и начинают развиваться в ускоренном темпе.

Таким образом, городская музыкальная культура Башкортостана, прежде всего, находящаяся на верхней ступени музыкальной иерархии русско-европейская академическая традиция, утвердила к 30-м годам XX века все основные формы функционирования профессионального 
искусства академического типа и оперы, в частности. В её пространстве, по её образцу и подобию в самом начале XX века начала формироваться татаро-башкирская культурная среда, прошедшая к периоду советского культурного строительства своеобразный путь развития и подготовившая тем самым основу для дальнейшего становления национального профессионального искусства.

\section{литературА $\sim 10$}

1. Атанова Л.П. Музыкальная культура Башкирии // Композиторы Башкирии / сост. Л.П. Атанова. Уфа, 1982. 128 с.

2. Атанова Л.П. Собиратели и исследователи башкирского музыкального фольклора. Уфа, 1992. 189 с.

3. Газиз Альмухаметов: Статьи. Воспоминания. Документы / авт.-сост. М.А. Идрисова. Уфа: Китап, 2008. 208 с.

4. Гарипова Н.Ф. Фортепианное исполнительство и образование в Уфе. Страницы истории. Уфа: Гилем, 2010. 248 с.

5. Имамутдинова 3.А. Культура башкир. Устная музыкальная традиция (чтение Корана, фольклор). М.: Гос. институт иск., 2000. 211 с.

6. История русской музыки. В 10 т. Т. 5. М.: Музыка, 1988. 519 с.

7. Карпова Е.К. Об изучении музыкального прошлого Башкирии: исторический обзор // Проблемы музыкальной науки. 2017. № 4. C. 151-158. DOI: 10.17674/1997-0854.2017.4.151-158.

8. Карпова Е.К. Становление традиций городской музыкальной жизни в Башкирии (XVIII - начало XIX века) // Народная традиционная культура: проблемы и перспективы: сб. ст. к 75-летию Ф.Х. Камаева. Уфа: УГИИ им. З. Исмагилова, 2019. С. 96-101.

9. Карпова Е.К., Рахимкулова М.Ф. Восточная музыкальная школа в Оренбурге. Страницы истории // Оренбуржье музыкальное. 2002. № 4 (8). С. 11-15.

10. Коваленко Г.А. История художественной культуры Башкортостана (20-30-е годы ХХ века). Уфа: ИИЯЛ, 2001. 179 с.

11. Кудаш С. Незабываемые минуты // Избранные сочинения. В 2 т. Т. 2. Уфа, 1989. С. 180-471. На башк. яз.

12. Маклыгин А.Л. Музыкальные культуры Среднего Поволжья: Становление профессионализма. Казань: КГК, 2000. 311 с.

13. Носорева Л.В. Музыка в жизни и творчестве С.Т. Аксакова // Аксаковские чтения (1996-1997). Уфа, 1997. С. 102-114.

14. Синенко С.Г. Уфа старая и новая. Популярная иллюстрированная энциклопедия. Уфа: Башкортостан, 2007. 272 с.

15. Театральная культура // Башкортостан: краткая энциклопедия. Уфа: Башк. энциклопедия, 1996. С. 72-73.

16. Хавторин Б.П. История музыкальной культуры Оренбургского края (XVIII-XX века). Оренбург: Южный Урал, 2004. 632 с.

17. Юнусова В.Н. Ислам Музыкальная культура и современное образование в России. М.: Хронограф, 1997. 152 с.

\section{Об авторе:}

Галина Гульназ Салаватовна, кандидат филологических наук, доцент кафедры этномузыкологии, Уфимский государственный институт искусств имени Загира Исмагилова (450008, г. Уфа, Россия), ORCID: 0000-0003-1297-5641, gulnazgalinas3@yandex.ru 


\section{a REFERENCES $\sim$}

1. Atanova L.P. Muzykal'naya kul'tura Bashkirii [Musical Culture of Bashkiria]. Kompozitory Bashkirii. Ed. by L.P. Atanova. Ufa, 1982. 128 p.

2. Atanova L.P. Sobirateli i issledovateli bashkirskogo muzykal'nogo fol'klora [Collectors and Researchers of Bashkir Musical Folklore]. Ufa, 1992. 189 p.

3. Gaziz Al'mukhametov: Stat'i. Vospominaniya. Dokumenty [Gaziz Almukhametov: Articles. Memories. Documents]. Comp. by M.A. Idrisova. Ufa: Kitap, 2008. 208 p.

4. Garipova N.F. Fortepiannoe ispolnitel'stvo i obrazovanie v Ufe Stranitsy istorii [Piano Performance and Education in Ufa. Pages of History]. Ufa: Gilem, 2010. 248 p.

5. Imamutdinova Z.A. Kul'tura bashkir. Ustnaya muzykal'naya traditsiya (chtenie Korana, fol'klor) [The Culture of Bashkirs. Oral Musical Traditions (the Reading of the Quran, and Folklore)]. Moscow: State Institute of Art Studies, 2000.211 p.

6. Istoriya russkoy muzyki v 10 tomakh. T. 5 [History of Russian Music. In 10 Vol. Vol. 5]. Moscow: Muzyka, 1988. 519 p.

7. Karpova E.K. Ob izuchenii muzykal'nogo proshlogo Bashkirii: istoricheskiy obzor [About the Study of the Musical Past of Bashkiria: A Historical Review]. Problemy muzykal'noj nauki / Music Scholarship. 2017. No. 4, pp. 151-158. DOI: 10.17674/1997-0854.2017.4.151-158.

8. Karpova E.K. Stanovlenie traditsiy gorodskoy muzykal'noy zhizni v Bashkirii (XVIII nachalo XIX veka) [Formation of Traditions of Urban Musical Life in Bashkiria (18th — Early 19th Century)]. Narodnaya traditsionnaya kul'tura: problemy i perspektivy. sb. st. $k$ 75-letiyu F.Kh. Kamaeva [Folk Traditional Culture: Problems and Prospects: Sat. Art. to the 75th Anniversary of F.Kh. Kamaev]. Ufa: Ufa State Institute of Arts named after Zagir Ismagilov, 2019, pp. 96-101.

9. Karpova E.K., Rakhimkulova M.F. Vostochnaya muzykal'naya shkola v Orenburge. Stranitsy istorii [Eastern Music School in Orenburg. Page of History]. Orenburzh'e muzykal'noe [Orenburg Musical]. 2002. No. 4 (8), pp. 11-15.

10. Kovalenko G.A. Istoriya khudozhestvennoy kul'tury Bashkortostana (20-30-e gody XX veka) [History of Artistic Culture of Bashkortostan (20-30s of the 20th Century)]. Ufa: Institute of History, Language and Literature, 2001. 179 p.

11. Kudash S. Nezabyvaemye minuty [Unforgettable Moments]. Izbrannye sochineniya. V $2 \mathrm{t}$. T. 2 [Selected Works. In 2 Vol. Vol. 2]. Ufa, 1989, pp. 180-471. (In Bashkir language)

12. Maklygin A.L. Muzykal'nye kul'tury Srednego Povolzh'ya: Stanovlenie professionalizma [Musical Cultures of the Middle Volga Region: Becoming a Professional]. Kazan: Kazan State Conservatory, 2000. $311 \mathrm{p}$.

13. Nosoreva L.V. Muzyka v zhizni i tvorchestve S.T.Aksakova [Music in the Life and Work of S.T. Aksakov]. Aksakovskie chteniya (1996-1997) [Readings on Aksakov (1996-1997)]. Ufa, 1997, pp. 102-114.

14. Sinenko S.G. Ufa staraya i novaya. Populyarnaya illyustrirovannaya entsiklopediya [Ufa is Old and New. Popular Illustrated Encyclopedia]. Ufa: Bashkortostan, 2007. 272 p.

15. Teatral'naya kul'tura [Theatrical Culture]. Bashkortostan: kratkaya entsiklopediya [Bashkortostan: A Brief Encyclopedia]. Ufa: Bashk. entsiklopediya, 1996, pp. 72-73.

16. Khavtorin B.P. Istoriya muzykal'noy kul'tury Orenburgskogo kraya (XVIII-XX veka) [History of Musical Culture of the Orenburg Region (18th-20th Centuries)]. Orenburg: Yuzhnyy Ural, 2004. $632 \mathrm{p}$.

17. Yunusova V.N. Islam Muzykal'naya kul'tura i sovremennoe obrazovanie v Rossii [Islam Music Culture and Modern Education in Russia]. Moscow: Khronograf. 1997. 152 p.

About the author:

Gulnaz S. Galina, Ph.D. (Philology), Associate Professor at the Ethnomusicology Department, Ufa State Institute of Arts named after Zagir Ismagilov (450008, Ufa, Russia), ORCID: 0000-0003-1297-5641, gulnazgalinas3@yandex.ru

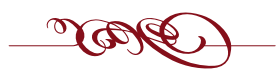

